\title{
Combination of a modified Hotz procedure with the Jones procedure decreases the recurrence of involutional entropion
}

This article was published in the following Dove Press journal:

Clinical Ophthalmology

I November 2012

Number of times this article has been viewed

\section{Kazuaki Nakauchi \\ Osamu Mimura}

Department of Ophthalmology, Hospital of Hyogo College of Medicine, Nishinomiya, Hyogo, Japan
Correspondence: Kazuaki Nakauchi

Department of Ophthalmology, Hospital of Hyogo College of Medicine, I- I

Mukogawa-cho, Nisihinomiya,

Hyogo 663-850I, Japan

Tel +8I 798456462

Fax +8I 798456464

Email nakauchi@hyo-med.ac.jp
Purpose: Involutional entropion is a common condition in Asian countries, including Japan. One cause of involutional entropion is weakening of the capsulopalpebral fascia (CPF). The aged, thin, membranous nature of the CPF limits the results of correction by the original Jones procedure (CPF tightening) alone, so we added the modified Hotz procedure to the entropion repair. We then compared the recurrence rates and operation times in corrections performed with and without this additional procedure.

Cases: From April 2010 to December 2011, one surgeon performed lower-lid surgery using the Jones procedure with the addition of the modified Hotz procedure. Fifteen patients (a total of 21 eyes) underwent this combined procedure. Previously, the same surgeon performed the Jones procedure alone for eight patients (a total of nine eyes).

Results: The average age of the two groups was 76.4 years, with an age range of 66-85 years. All cases reported acceptable ciliary orientation at the end of the surgery. However, patients who underwent the Jones procedure alone (nine eyes total) reported three cases of recurrence after at least 6 months of follow-up. Patients who underwent the combined procedure reported two complications: one recurrence and one ectropion. The recurrence rate was $5 \%$. The Jones procedure using eyelid pinch required an average of 22.6 minutes to complete; the combined method required 33.4 minutes to complete. Conclusion: The combined method resulted in a significantly higher success rate than the Jones procedure alone $(P<0.05)$. The $5 \%$ failure rate of the combined method was found to be superior to the $30 \%$ recurrence rate of the Jones procedure. As a result, the Hotz procedure enhanced the results of the entropion correction and required only 10 additional minutes of surgery. We now perform this combined procedure for all cases.

Keywords: Jones procedure, Hotz procedure, entropion, recurrence, operation time

\section{Purpose}

Involutional entropion is a common condition in Asian countries, including Japan. ${ }^{1}$ One cause of involutional entropion is weakening of the capsulopalpebral fascia (CPF). ${ }^{2}$ The aged, thin, membranous nature of the CPF limits the results of correction by the original Jones procedures alone, so we added the modified Hotz procedure to the entropion repair. Our modified Hotz procedure binds the dermis to the tarsus and corrects the ciliary orientation. To determine the efficiency of the additional Hotz procedure, we compared the recurrence rates and operation times in corrections performed with and without this additional procedure.

\section{Cases}

From April 2010 to December 2011, one surgeon performed lower-lid surgeries using Jones CPF-tightening procedure with the addition of the modified Hotz procedure 
(ciliary-everted suture). Fifteen patients (six male and nine female) underwent this combined procedure for a total of 21 eyes (six right eye only, three left eye only, six both eyes).

From January 2010 to September 2010, the same surgeon performed the Jones procedure alone on eight patients (four male and four female) for nine eyes (six right eye only, one left eye only, one both eyes).

The follow-up after surgery continued for at least 6 months.

\section{Surgery}

After injection of $1 \%$ xylocaine with $0.01 \%$ epinephrine, the lower-eyelid skin pinch is cramped. A horizontal skin incision is made $5 \mathrm{~mm}$ below the eyelash line, and the orbicularis under the skin is exposed. The layer of the orbicularis is identified by 4-0 silk-suture traction. The portion of the orbicularis over the tarsus is removed, and the layer between the orbicularis and the septum-CPF complex is separated.

Prior to dissection of the posterior CPF layer, the CPF complex is cut at tarsal height, and the conjunctiva is visible at the bottom layer of the lower eyelid. Between the CPF and conjunctiva, a sparse red tissue layer resembling the Müller muscle sometimes exists. This is thought to be the posterior layer of the CPF. Without puncturing the conjunctiva, dissections along the layer are completed (Figure 1A).

Next, the orbital fat layer beneath the septum is identified, and the layer is dissected inferiorly approximately $7-8 \mathrm{~mm}$ from the tarsus (Figure 1B). The anterior CPF layer exists just under the fat layer.

After the exposure of the anterior layer, an advancement of approximately $5 \mathrm{~mm}$ (tarsus-CPF tightening) is performed with three mattress sutures of 6-0 polysorb (Figure 1C and D).

After the Jones procedure with CPF is completed, the modified Hotz procedure (ciliary-everted suture) is performed between the tarsus and solid dermis tissue (Figure 1E). Normally, five or six stitches are used.

After hemostasis is achieved, the eyelid pinch is removed. Finally, the skin is closed with a 7-0 nylon suture. Normally, six or seven stitches are used. The ciliary directions are shown to be corrected after the operation (Figure 1F).

Figure 2 shows the CPF advancement on the tarsus (green line) and the Hotz rotation suture (blue line).

\section{Results}

The average age of two groups was 76.4 years, with an age range of $66-85$ years. All cases showed acceptable ciliary orientation at the end of the surgery.
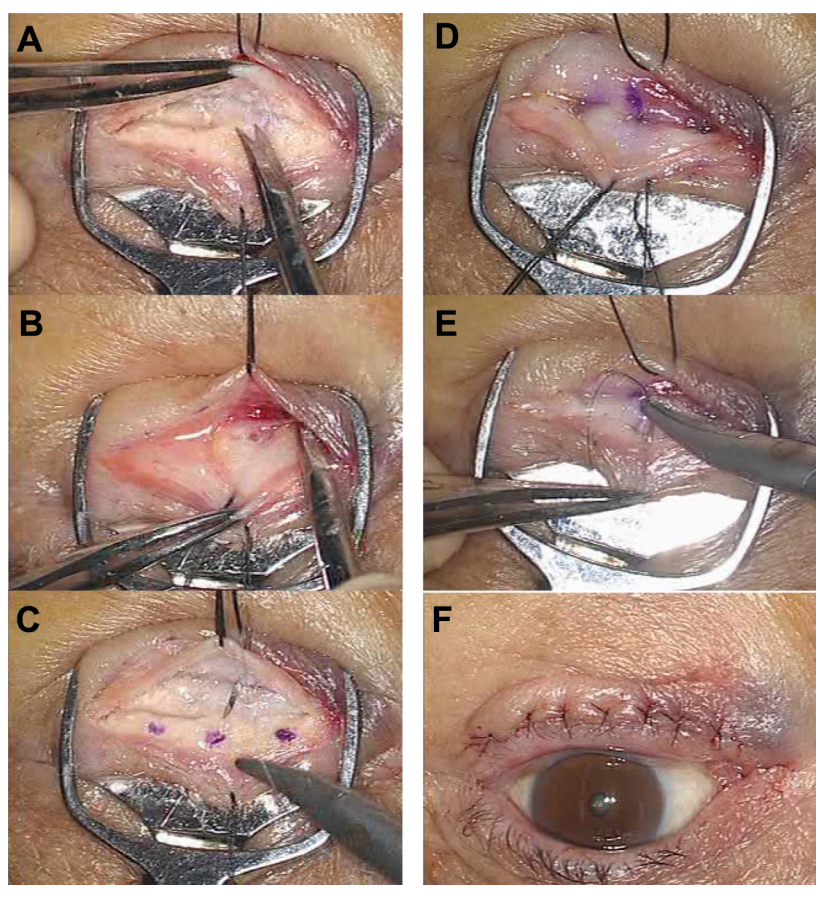

Figure I (A-F) These photographs help us understand the actual surgery. Eyelid pinch cramped the lower eyelid for hemostasis, and 4-0 silk sutures retracted the eyelid skin for the separation of the skin and the orbicularis. (A) The dissection of the posterior layer of the capsulopalpebral fascia (CPF). First, cut the CPF complex at the inferior border of the tarsus. Visualize the conjunctiva on the silver plate of the pinch and dig along the layer. Avoid puncturing the conjunctiva. (B) The dissection of the anterior layer of the CPF. Second, locate the orbital fat layer beneath the septum. Dig down that layer inferiorly, approximately $7-8 \mathrm{~mm}$ from the tarsus. (C and D) CPF advancement. Three points were marked with a skin marker on the tarsus and $5 \mathrm{~mm}$ inferiorly from the cut end of the CPF. The dissected CPF was sutured to the tarsus with three sutures of 6-0 polysorb. (E) Ciliary everted suturing. Nylon suture (7-0) tied dermis and tarsus, resulting in eversion of the cilia. Normally, five or six stiches are needed. (F) Direction of cilia at the end of the surgery. All cilia are corrected to their normal positions. Palpebration has no influence on the ciliary position.

The cases in which the Jones procedure alone was used (average age 76.0 years, nine eyes total) reported three recurrences, which corresponds to a recurrence rate of over $30 \%$ at a follow-up duration of at least 6 months. The recurrent cases required an eyelid margin split or a lateral tarsal split for additional correction.

The cases in which the combination method was used (average age 76.7 years, 21 eyes total) reported two cases of complications (one recurrence and one ectropion), which corresponds to a recurrence rate of $5 \%$. The one instance of recurrence occurred 9 months after surgery and required an eyelid margin split and an additional Hotz procedure for correction. The instance of ectropion presented with severe horizontal laxity before surgery that developed into ectropion 3 months after surgery. Although the direction of the cilia was corrected, this eyelid required a lateral tarsal strip (LTS). The Jones procedure used an eyelid pinch and required an average of 22.6 minutes to complete; the combined method required an average of 33.4 minutes to complete. 


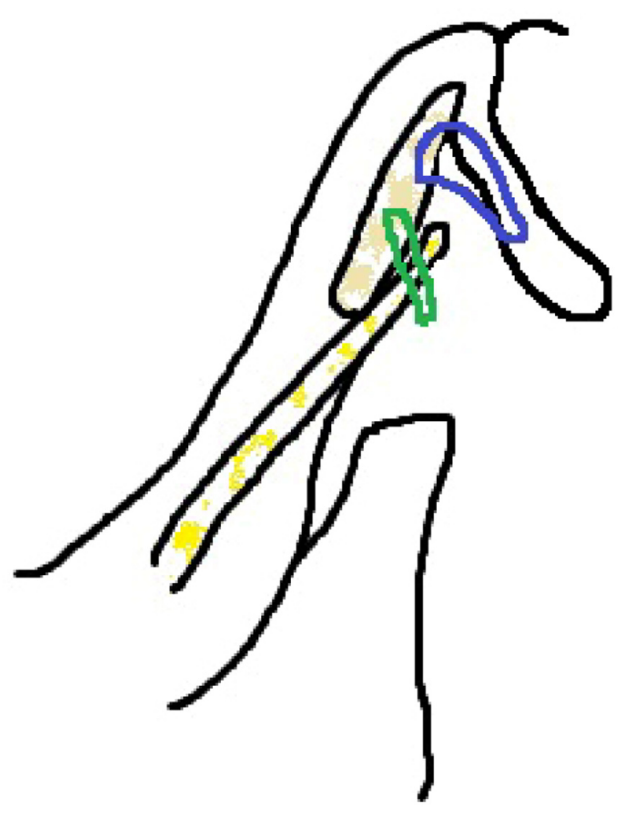

Figure 2 A simple diagram of the lower eyelid and our combination procedure. Notes: The pink round structure represents the tarsus, and the thin yellow structure represents the capsulopalpebral fascia (CPF). The green circle shows the binding location of the CPF and the tarsus. The blue circle shows the ciliary everted suture, which ties the dermis to the tarsus.

\section{Conclusion}

The Jones procedure was first reported in $1963 .{ }^{3}$ However, this procedure was not popular in Japan until it was disseminated by Kakizaki et al. ${ }^{4}$

The Jones procedure tightens the CPF by plication, thus reinforcing the vertical traction power of the lower-lid ligaments. However, the CPF often presents as a thin and membranous structure in aged patients and is not strong enough to correct the lower-lid direction permanently. Kakizaki recommended an anteriorposterior double-layer advancement by means of this weakness. ${ }^{5}$ Another study has reported rates of recurrence of $7 \%-15 \%$ after CPF plication. ${ }^{6,7}$ The Jones procedure in our hospital resulted in a higher recurrence rate of $30 \%$, indicating that this an unreliable procedure.

First, we retrospectively compared two (recurrent and nonrecurrent) cases during surgery. The surgical videos showed that the former case had a slightly thin CPF and the latter one had a slightly thick CPF. However, the direction of the cilia at the end of the surgeries was not different between these cases. Thus, CPF thickness is not an appropriate tool for making decisions about additional procedures.

Reinforcement of both the vertical and horizontal ligaments is ideal. The vertical laxity is corrected by the Jones procedure, and the horizontal laxity is corrected by the LTS. ${ }^{8}$ However, the
LTS is not an easy technique, and the operation is painful and bloody. Thus, it is not recommended to use LTS in all cases.

The Wheeler procedure is a more popular technique for horizontal plication of the eyelid orbicularis. ${ }^{9}$ However, the utility of this procedure is also decreased by the aging process, and the experimental recurrence rate is high. ${ }^{10}$ Moreover, the original Jones procedure removes the orbicularis situated over the tarsus and is incompatible with the Wheeler procedure.

The remaining potential technique is the Hotz procedure. Previous studies, including our own, report recurrence rates of less than $10 \%$ in congenital entropion patients. ${ }^{11,12}$ Jones et al introduced a modified procedure 10 years after the establishment of the original technique. His modified method tied skin-tarsus-CPF-skin. ${ }^{13}$ In 1974, Schaefer recommended connecting the lid skin to the tarsus by taking a bite through the lower edge of the skin muscle. ${ }^{14}$ We selected dermis just under the side of the cilia to tarsus suture, which is a relatively solid tissue-binding site.

This combination method results in a significantly higher success rate than when the Jones procedure alone is used. The $P$-value was 0.034 , as calculated by the chi-square test for independence. A 5\% recurrence rate is a much more desirable result compared to the $30 \%$ recurrence rate resulting from application of the simple procedure. The additional Hotz procedure requires only 10 additional minutes in surgery, making it one of the best choices among the procedures discussed here. We will now perform this combined procedure for all involutional entropion cases, following a half-year transitional phase.

Because no technique achieved a zero rate of recurrence, additional steps taken to correct the cases of recurrence are outlined. When the cilia are located too close to the eyelid margin, we perform the margin split procedure. When the lower eyelid exhibits too much laxity and requires horizontal correction to increase its strength, we add LTS to the lateral orbital periosteum. Subsequent to this procedure, we perform ciliary electrolysis or the Wojno ciliary removal procedure. ${ }^{15}$ It is essential to have a variety of additional techniques available to correct issues of recurrence in the treatment of entropion.

\section{Disclosure}

The authors report no conflicts of interest in this work.

\section{References}

1. Carter SR, Chang J, Aquilar GL, Rathbun JE, Seiff SR. Involutional entropion and ectropion of the Asian lower eyelid. Ophthal Plast Reconstruct Surg. 2000;16:45-49. 
2. Kocaoglu FA, Katircioglu YA, Tok OY, Pulat H, Omek F. The histopathology of involutional ectropion and entropion. Can J Ophthalmol. 2009;44:677-679.

3. Jones LT, Reeh MJ, Tsujimura JK. Senile entropion. Am J Ophthalmol. 1963;55:463-469.

4. Kakizaki H, Zako M, Mito H, Katori N, Iwaki M. Magnetic resonance imaging of pre- and postoperative lower eyelid states in involutional entropion. Jpn J Ophthalmol. 2004;48:363-367.

5. Kakizaki H. Modified operation to correctly detect and fix the lower eyelid retractor in involutional entropion. Jpn J Ophthalmol. 2005;49:327-328.

6. Altieri M, Kingston AE, Bertagno R, Altieri G. Modified retractor plication technique in lower lid entropion repair. Can J Ophthalmol. 2004;39:650-655.

7. Boboridis K, Bunce C, Rose GE. A comparative study of two procedures for repair of involutional lower lid entropion. Ophthalmology. 2000;107:959-961

8. Barnes JA, Bunce C, Olver JM. Simple effective surgery for involutional entropion suitable for the general ophthalmologist. Ophthalmology. 2006;113:92-96.
9. Brackup AH. Modified Wheeler orbicularis overlap procedure for senile entropion. Ophthalmic Surg. 1979;10:35-40.

10. Olali C, Burton V, Samalila E. Involutional lower eyelid entropion: combined Wheeler's and Wedge resection of tarsal plate. West Afr $J$ Med. 2010;29:117-119.

11. Nakauchi K, Mimura O. Fish-tail resection for treating congenital entropion in Asians. Clin Ophthalmol. 2012;6:831-835.

12. Sundar G, Young SM, Tara S, Tan AM, Amrith S. Epiblepharon in east Asian patients: the Singapore experience. Ophthalmology. 2010;117:184-189.

13. Jones LT, Reeh MJ, Wobig JL. Senile entropion. Am J Ophthalmol. 1972;74:327-329.

14. Schaefer AJ. Senile entropion. Ophthalmic Surg. 1974;5:33-38.

15. Wojno TH. Lid splitting with lash resection for cicatrical entropion and trichiasis. Ophthal Plast Reconstr Surg. 1992;8:287-289.
Clinical Ophthalmology

\section{Publish your work in this journal}

Clinical Ophthalmology is an international, peer-reviewed journal covering all subspecialties within ophthalmology. Key topics include: Optometry; Visual science; Pharmacology and drug therapy in eye diseases; Basic Sciences; Primary and Secondary eye care; Patient Safety and Quality of Care Improvements. This journal is indexed on Submit your manuscript here: http://www.dovepress.com/clinical-ophthalmology-journal

\section{Dovepress}

PubMed Central and CAS, and is the official journal of The Society of Clinical Ophthalmology (SCO). The manuscript management system is completely online and includes a very quick and fair peer-review system, which is all easy to use. Visit http://www.dovepress.com/ testimonials.php to read real quotes from published authors. 